\title{
Second-generation long-acting injectable antipsychotics in schizophrenia: patient functioning and quality of life
}

This article was published in the following Dove Press journal:

Neuropsychiatric Disease and Treatment

19 April 2016

Number of times this article has been viewed

\author{
Cristiana Montemagni ${ }^{1,2}$ \\ Tiziana Frieri ${ }^{1,2}$ \\ Paola Roccal, ${ }^{1,2}$ \\ 'Department of Neuroscience, Unit \\ of Psychiatry, University of Turin, \\ ${ }^{2}$ Department of Mental Health, \\ Azienda Sanitaria Locale (ASL) Torino \\ I (TOI), Azienda Ospedaliero- \\ Universitaria (AOU) Città della Salute \\ e della Scienza di Torino, Turin, Italy
}

Correspondence: Paola Rocca Department of Neuroscience, Unit of Psychiatry, University of Turin, Via Cherasco II, I0I26 Turin, Italy

Tel +390116336780

Fax +390 II 673473

Email paola.rocca@unito.it

\begin{abstract}
Long-acting injectable antipsychotics (LAIs) were developed to make treatment easier, improve adherence, and/or signal the clinician when nonadherence occurs. Secondgeneration antipsychotic LAIs (SGA-LAIs) combine the advantages of SGA with a long-acting formulation. The purpose of this review is to evaluate the available literature concerning the impact of SGA-LAIs on patient functioning and quality of life (QOL). Although several studies regarding schizophrenia patients' functioning and QOL have been performed, the quantity of available data still varies greatly depending on the SGA-LAI under investigation. After reviewing the literature, it seems that SGA-LAIs are effective in ameliorating patient functioning and/or QOL of patients with schizophrenia, as compared with placebo. However, while methodological design controversy exists regarding the superiority of risperidone LAI versus oral antipsychotics, the significant amount of evidence in recently published research demonstrates the beneficial influence of risperidone LAI on patient functioning and QOL in stable patients and no benefit over oral treatment in unstable patients. However, the status of the research on SGA-LAIs is lacking in several aspects that may help physicians in choosing the correct drug therapy. Meaningful differences have been observed between SGA-LAIs in the onset of their clinical efficacy and in the relationships between symptoms and functioning scores. Moreover, head-to-head studies comparing the effects of SGA-LAIs on classical measures of psychopathology and functioning are available mainly on risperidone LAI, while those comparing olanzapine LAI with other SGALAIs are still lacking. Lastly, some data on their use, especially in first-episode or recent-onset schizophrenia and in refractory or treatment-resistant schizophrenia, is available.
\end{abstract}

Keywords: outcome, first-episode schizophrenia, recent-onset schizophrenia, treatment resistant schizophrenia

\section{Introduction}

The World Health Organization classifies schizophrenia among the top ten causes of years lost due to its disability. ${ }^{1}$ This is caused by its specific onset in early adulthood and longterm persistence or sudden mutation of symptoms in at least two-thirds of patients. ${ }^{2}$

Most patients are unable to reach at least one milestone, such as being in a stable relationship, having full-time competitive employment, or having self-supported independent living. A review of eight controlled trials has highlighted the fact that rates of unemployment for patients with schizophrenia, although they have good support, ranged from only $30 \%$ to $80 \%$, with a median of $60 \%$ across these studies, ${ }^{3}$ even in the context that the majority of them frequently expressed their keenness to work. ${ }^{4,5}$ Otherwise, rates of marriage for patients with schizophrenia were reported to range from about $5 \%$ to $30 \%$, with the majority ranging between $15 \%$ and $30 \% .^{6-12}$ 
The early phase of schizophrenia, including the first 2 years up to 5 years after the onset, is thought to be essential in determining long-term prognosis. ${ }^{13}$

Symptomatic relapse in schizophrenia can be destructive: the setback can be dramatic, often leading to increased use of outpatient services ${ }^{14}$ and resulting in hospitalization. ${ }^{6,14,15} \mathrm{In}$ addition, relapse can be strictly connected with a biological risk. It has been hypothesized that active psychosis reflects a period of disease progression to the extent that patients may not come back to their previous level of function and treatment refractoriness may be evident. ${ }^{16,17}$

Poor adherence is considered to be the most frequent cause of relapse in schizophrenia. ${ }^{18,19}$ When patients discontinue their medications, even after the first episode, the risk for symptomatic relapse increases dramatically, by nearly five times. ${ }^{20}$

In clinical settings, poor compliance is common, especially in the early stages of the disease, ${ }^{21-24}$ with between $40 \%$ and $60 \%$ of patients with schizophrenia partially or totally noncompliant with oral antipsychotics, ${ }^{25,26}$ and no real difference between first-generation antipsychotics and second-generation antipsychotics (SGA) was found. ${ }^{27}$ The Clinical Antipsychotic Trials of Intervention Effectiveness study has highlighted that up to $74 \%$ of people affected by schizophrenia start to discontinue their medications after 18 months; also, the European First Episode Schizophrenia Trial found that up to $42 \%$ of patients stopped their therapy within 1 year after the first psychotic episode. ${ }^{28,29}$

Nonadherence has a wide variation, probably due to differences in the targeted population, definitions, and measurement methods. However, it has been noticed that studies using more strict measurement methodology, such as pill count, electronic monitoring, and blood drug level, often indicate higher levels of nonadherence. ${ }^{30-33}$ Moreover, the duration of follow-up certainly has a clear influence on the observed frequencies of nonadherence. Therefore, for different reasons, it is reasonable to consider that adherence is much lower in routine care than in clinical trials. ${ }^{34}$

Managing nonadherence must be patient specific. Usually it needs quite a few strategies; however, shared decision making between the patient and physician is virtually always involved. Long-acting injectable antipsychotics (LAIs) were developed to make treatment easier and enhance adherence and/or signal the physician when nonadherence occurs. ${ }^{35}$

\section{Current guidelines}

Majority of the available guidelines and algorithms (with the exception of The Schizophrenia Patient Outcomes Research Team (PORT) project, 2009) recommend LAIs for patients who need maintenance treatment and express a preference for them over oral antipsychotics, and/or when it is necessary to improve adherence to medication, ${ }^{36-39}$ with a few guidelines factually suggesting a switch from oral antipsychotics to LAIs during maintenance treatment. ${ }^{40,41}$

However, the Texas Medication Algorithm Project for antipsychotics in schizophrenia ${ }^{42}$ and the Canadian guidelines recommend LAIs in all phases of schizophrenia, also in the first 2-5 years. ${ }^{43}$ Lastly, the French Association for Biological Psychiatry and Neuropsychopharmacology recommends LAI as first-line treatment to patients with schizophrenia during maintenance treatment. ${ }^{44}$

\section{Efficacy/effectiveness of LAls versus oral antipsychotics}

Although LAIs have been developed to enhance adherence and/or signal the physician when nonadherence occurs, evidence regarding their superiority over oral antipsychotics in terms of relapse prevention is ambivalent and also depends on trial design. Even though a meta-analysis has shown a significant benefit of LAI versus oral antipsychotics, ${ }^{45}$ two recent meta-analyses of randomized controlled trials (RCTs) have highlighted both LAIs and oral antipsychotics were effective in relapse prevention and hospitalization. ${ }^{46,47}$ Two large RCTs have shown a longer time to relapse with an LAI versus oral antipsychotics. ${ }^{48,49}$

Relevant advantages of LAIs versus oral antipsychotics in reducing psychiatric hospitalization have been shown by a recent meta-analysis performed by Kishimoto et $\mathrm{al}^{50}$ on 25 mirror-image studies. However, the authors admit that mirror-image studies may also be biased by the fact that treatment status is not blinded, thresholds for hospitalization can modify over time, and patients always start LAI after a period of time in which although oral antipsychotics are taken daily, the outcomes are considered suboptimal. It has also been noted that reverse mirror-image studies (ie, from LAI to oral formulation) are lacking.

The majority of cohort studies detected lower hospitalization rates and/or longer time to discontinuation with LAI, even though several studies noted equivalent or better outcomes for oral medication, and a prescribing/channeling bias in cohort studies suggests that patients treated with LAI have a more severe stage of illness.

Moreover, it has been hypothesized that oral antipsychotics may be as effective as LAIs when adherence and bioequivalence are secured, which appears plausible because LAIs are designed to mimic the pharmacokinetics of oral compounds in adherent patients. ${ }^{51}$

In their recent review, Haddad et $\mathrm{al}^{35}$ concluded that strengths and weaknesses are inherent in each of the three 
different study designs. The typical RCTs cannot necessarily be the best way to evaluate treatments that are considered useful in reducing nonadherence, because of selective recruitment of more adherent patients and they can also modify ecology of the treatment. Treatment is not carried out in a setting in which real-world conditions are preserved. Otherwise, weaknesses of observational studies involve lack of blinding and difficulty estimating the effectiveness of treatment without considering confounders and prescribing bias. The best approach to evaluate comparative effectiveness can be alternative "effectiveness trials" more closely resembling real life. An ideal solution should involve different aspects: trials should be prospective, should be performed at several sites, should use broad inclusion criteria, without requiring a lot of data, should be focused on patients in an early phase of disease, and should follow patients for at least 2 years using relapse and/or hospitalization as the primary outcome measures. ${ }^{51}$

\section{LAI, patient functioning, and quality of life}

Although patients with schizophrenia treated with LAIs demonstrated symptomatic improvement, the improvement is not always associated with functional improvement. ${ }^{52-55}$ It has been shown that in patients with stable schizophrenia, compliance is mainly related to recognition of the positive effects of the pharmacological therapy on daily life.$^{56,57}$ In particular, during long-term therapies, subjective perception of general wellness and quality of life (QOL) are clear factors influencing and maintaining compliance to treatment. ${ }^{58}$ Consequently, a significant role has been assigned recently to the notion of subjective well-being and QOL, even in patients treated with antipsychotics. ${ }^{59}$ Wellknown additional factors determining poor compliance are: side effects (mainly extrapyramidal symptoms), complex treatment plans, and misunderstanding of dosage schemes. ${ }^{60}$ Considering that the introduction of SGA partially reduced the incidence of side effects, the development of LAIs should further simplify the dosage plans, thus reducing mistakes and improving the regular intake of medications. ${ }^{61}$ It seems clear that SGA-LAIs seem to put together the advantages of SGA with a long-acting formulation. ${ }^{62}$

Thus, the purpose of this paper is to review the available literature regarding SGA-LAIs, evaluating patient functioning and QOL.

\section{Materials and methods}

An electronic search was conducted through Medline and PubMed to identify articles relevant to the role of SGALAIs on patient functioning and QOL in schizophrenia. Keywords used were "second-generation long-acting injectable antipsychotics", "second-generation depot", "social functioning", "quality of life", "risperidone long-acting", "paliperidone long-acting”, “olanzapine long-acting”, "aripiprazole long-acting”, "schizophrenia”, "first-episode schizophrenia", "recent onset schizophrenia", "refractory schizophrenia", and "treatment-resistant schizophrenia". This procedure was supplemented with a manual search of the bibliography included in the articles found, and of relevant reviews, in order to gain access to additional references. Studies with vaguely described interventions or inadequate outcome information were excluded. The methodological quality of the studies was assessed according to the following variables: diagnostic criteria used, demographic representation of indicators, study design (eg, sample size, control groups, direct vs indirect assessment), assessor's characteristics (eg, bias and blindness), and assessment tools (eg, outcome measures). The design of a study was considered "controlled" when treatments were comparatively evaluated.

We identified 60 English language articles published between January 1998 (when the first SGA-LAI was launched) and December 2015.

This article represents a clinically oriented narrative review of currently available evidence, first including randomized controlled studies and open-label studies, followed by observational ones. We concluded reporting evidence in specific populations, that is, first-episode or recent-onset schizophrenia, and refractory or treatment-resistant schizophrenia (TRS).

\section{Results}

Although several studies on schizophrenia patients' functioning and QOL have been performed, the quantity of available data still varies greatly depending on the SGA-LAI under investigation.

\section{Risperidone LAI}

See Table 1 for the effects of risperidone LAI (RLAI) on functioning and QOL.

\section{RCTs and open-label studies \\ Stable patients}

Significant improvements were induced by RLAI in five of the 36-item Short Form Health Survey (SF-36) domains (emotional role, bodily pain, social functioning, general health, and mental health) after 8 weeks and in all SF-36 domains after 12 weeks, when compared with placebo (the US general population). ${ }^{63}$ These results are in line with those of Fleischhacker et al, ${ }^{64}$ who reported an improvement of SF-36 after 12 months of RLAI treatment. 


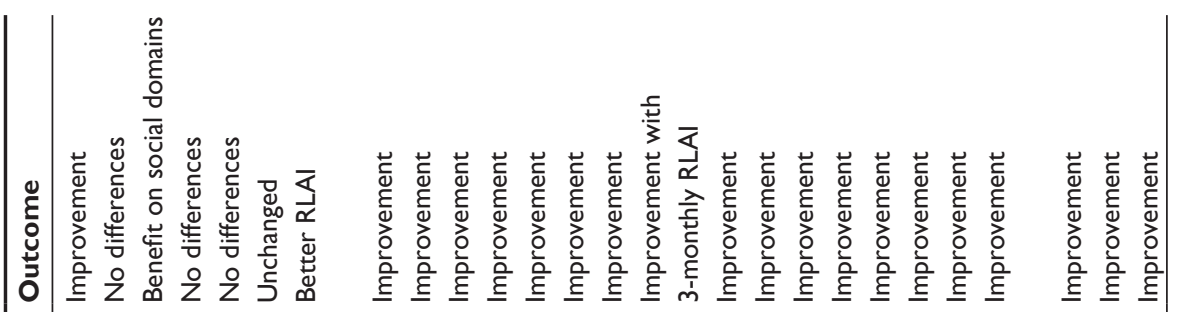

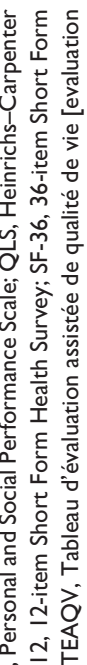

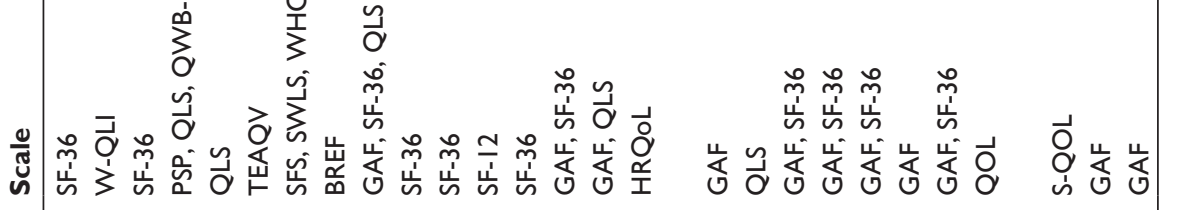

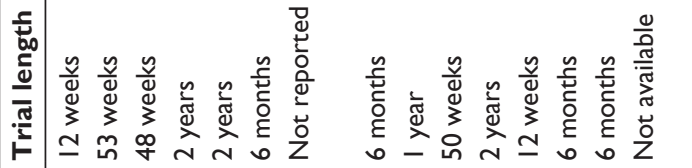

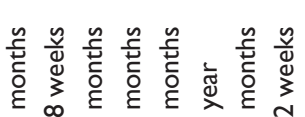

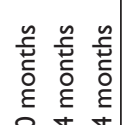

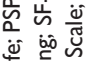

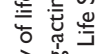

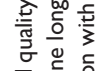

$\stackrel{2}{\stackrel{2}{2}}$

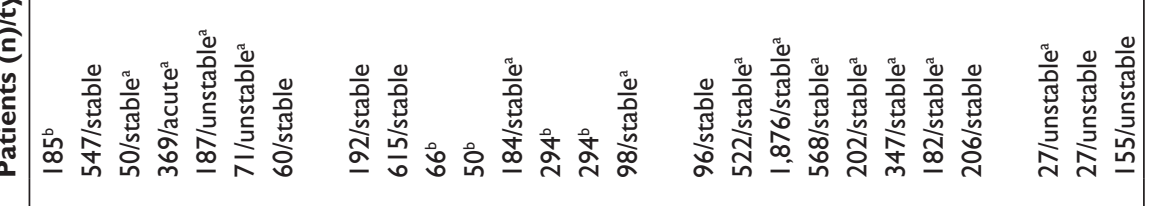

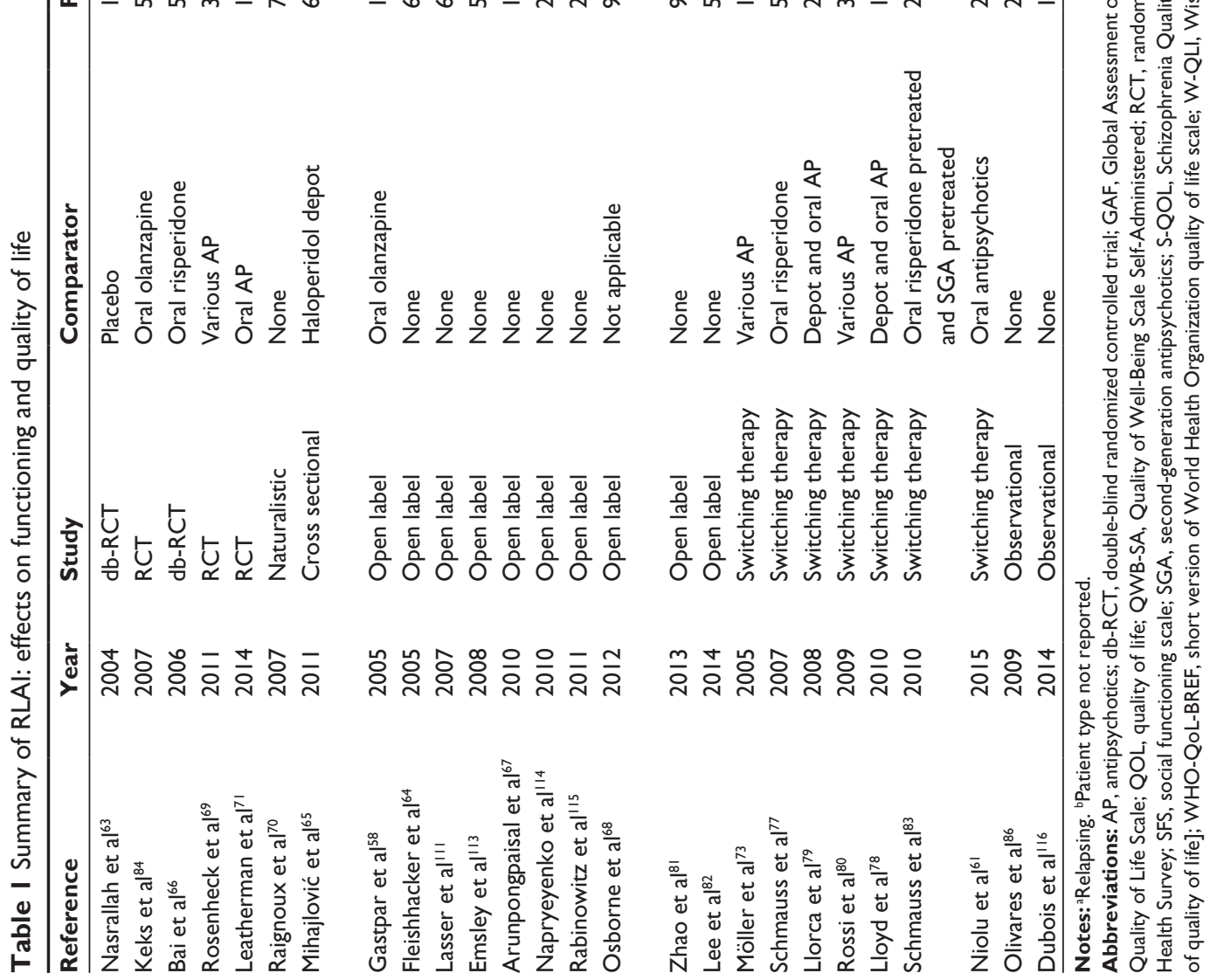


A cross-sectional study highlighted higher scores in 30 patients on RLAI concerning social activities and satisfaction with themselves, their health, and sleep, when compared to 30 patients treated with haloperidol depot, with no statistically significant difference found in the QOL scales (social functioning scale, satisfaction with life scale, and the short version of World Health Organization QOL scale [WHO-QoL-BREF]). ${ }^{65}$

\section{Hospitalized stable patients}

In a 12 -week randomized, single-blind study, 50 inpatients with stable schizophrenia, previously treated with oral risperidone for at least 3 months, were randomized to the RLAI and oral risperidone groups. ${ }^{66}$ Patients in the RLAI arm displayed significantly higher scores on SF-36 social life domains, improvement of side effects, and reduced prolactin levels.

In a multicenter, open-label, single-arm study, 184 patients were treated with RLAI; they got significantly better over 12 weeks, as reflected by the finding that $53.2 \%$ of patients were considered as "not ill" or "borderline ill" at the endpoint, when compared to $5.9 \%$ at baseline. ${ }^{67} \mathrm{SF}-36$ scale got better in all domains except one, consisting in bodily pain.

Osborne et $\mathrm{l}^{68}$ reported that an increasing time interval between LAI injections (3-month interval vs 2- and 4-weeks intervals) was associated with the highest QOL scores.

\section{Unstable patients}

On the other hand, a comparative clinical trial indicated that RLAI was not superior to oral antipsychotics when Heinrichs-Carpenter Quality of Life Scale (QLS), Personal and Social Performance Scale (PSP), and self-reported Quality of Well-Being scale were used to assess QOL and functioning in unstable patients with schizophrenia. ${ }^{69}$ This was confirmed by a naturalistic study conducted in 71 inpatients of three psychiatric hospitals in Aquitaine, who were unstable or considered to be noncompliant with their pharmacological treatment. Even though 46\% patients treated with RLAI "strongly" to "very strongly" improved on Clinical Global Impression Scale (CGI-S) after 6 months, patients claimed that their QOL, as assessed by the Tableau d'évaluation assistée de qualité de vie, did not change, when compared with baseline..$^{70} \mathrm{~A}$ long-term randomized trial of 187 unstable patients with schizophrenia who had been hospitalized within the past 2 years or judged to be at risk for hospitalization because of increasing psychiatric service use found no benefit of RLAI as compared with oral antipsychotics in preventing or delaying time to psychiatric hospitalizations or on QOL as assessed through QLS after 2 years. ${ }^{71}$

Only in a recent study on 9 patients out of 27 nonadherent patients switched to RLAI, an improvement of QOL and wellness was demonstrated by the increase in mean values of Subjective Well-being Under Neuroleptic Treatment scale and Schizophrenia Quality of Life scales after 8 and 18 months of treatment, respectively, that was simultaneous with the control of symptomatology. ${ }^{61}$

\section{Switching therapy}

Two international trials have been conducted in this field of research.

In the Switch To Risperidone Microspheres (StoRMi) trial, an international, 6-month, open-label trial on patients with schizophrenia who were switched from oral or firstgeneration antipsychotic-LAI to RLAI for lack of efficacy, side effects, or noncompliance, improvements were observed in Positive and Negative Syndrome Scale (PANSS) total and subscale scores, Global Assessment of Functioning (GAF), QOL, treatment satisfaction, and hospitalization. ${ }^{72}$ Moreover, patients showed an overall amelioration of QOL related to the health status and a significant increase in fields such as mental health, vitality, social activities, and role limitations secondary to emotional status. ${ }^{73}$ These results were confirmed in a third subanalysis of the StoRMi trial ${ }^{74}$ on 842 patients with predominantly negative symptoms at baseline (PANSS negative subscale score $\geq 21$ ) and in fourth post hoc analysis in 52 elderly patients ( $\geq 65$ years) ${ }^{75}$ In a fifth separate analysis from the StoRMi trial on 529 patients $^{76}$ after 18 months, $33 \%$ of patients achieved symptomatic remission for at least 6 months; predictors of best outcome ( $21 \%$ of patients) were baseline symptom severity, baseline functioning, country, schizophrenia type, and early positive treatment course. In another subgroup analysis of the StoRMi trial, further improvement in symptom control, GAF scores, and SF-36 mental component summary score could be seen after a change to RLAI in 568 clinically stable patients previously treated with oral risperidone. ${ }^{77}$

In a second international, nonrandomized trial following unsatisfactory treatment with oral antipsychotics, 182 UK patients with schizophrenia or other psychotic disorders, symptomatically stable on antipsychotic medication, were switched to RLAI. Compared with baseline, significant improvement over 6 months was observed concerning illness severity (PANSS total and subscale scores), patient functioning (GAF), health-related QOL, and patient satisfaction. ${ }^{78}$ 
These results are confirmed by other studies conducted in France, ${ }^{79}$ Italy, ${ }^{80}$ Japan,${ }^{81}$ and Korea,${ }^{82}$ with longer follow-up (52 weeks), ${ }^{80}$ associated with psychosocial intervention. ${ }^{81}$

In a French study, 202 adults with schizophrenia or other psychotic disorders, who were clinically stable for 1 month or more on their previous medication (SGA [65\%], depot [34\%], and oral [9\%] conventional neuroleptics) and requiring a change of treatment, were directly switched to LRAIs and experienced statistically significant improvement of disease symptoms, patient functioning (GAF), movement disorders, health-related QOL (SF-36), and patient satisfaction with treatment after 6 months. ${ }^{79}$ Similar findings as regards PANSS total and subscales, GAF, and CGI-S scores have been found in a 52-week, open-label prospective trial on 347 stable patients switching directly to RLAI from any previous antipsychotics. ${ }^{80}$

In a clinical trial assessing the effectiveness of add-on Comprehensive Psycho-educational Approach and Scheme Set in 96 Japanese patients with schizophrenia treated with RLAI, $80 \%$ of patients showed significant improvements in Brief Psychiatric Rating Scale (BPRS) negative and general subscale scores, and GAF from baseline to 6 months. ${ }^{81}$ An open-label, 48-week, prospective study on 522 patients with schizophrenia or schizoaffective disorder from 63 centers in South Korea highlighted clinical improvements in symptom severity (PANSS, CGI-S) and QOL (Schizophrenia Quality of Life scale). ${ }^{82}$

Two studies focused only on olanzapine-pretreated patients or risperidone-pretreated patients. In the first one, 134 patients out of 192 who were previously treated with olanzapine and receiving RLAI without a run-in period of oral risperidone completed the study. ${ }^{58}$ Treatment with RLAI was also associated with significant improvements in GAF, patient satisfaction with treatment, and SF-36. In the second, open-label study on 206 stable patients receiving oral risperidone or other SGA (olanzapine, quetiapine, amisulpride, ziprasidone) and being switched to RLAI for 12 weeks, patients pretreated with other SGA showed a stronger clinical benefit, improved satisfaction, and QOL from direct transition to RLAI, as compared with those previously treated with oral risperidone. ${ }^{83}$ However, a randomized, controlled, open-label study involving individuals affected by schizophrenia or schizoaffective disorder showed that RLAI and oral olanzapine induced comparable mean scores of the Wisconsin Quality of Life Index. ${ }^{84}$

\section{Observational studies}

The 2-year, prospective, observational, electronic Schizophrenia Treatment Adherence Registry (e-STAR) revealed that as compared with oral olanzapine or oral risperidone, RLAI produced better treatment retention and greater improvement in clinical symptoms and functioning in 1,345 patients with schizophrenia in Spain. ${ }^{85}$

Data from the Australian cohort of e-STAR showed, throughout a 24-month period, that initiation of RLAI was associated with improved patient functioning and illness severity in 784 patients with schizophrenia or schizoaffective disorder. During the entire study, improved outcomes have been observed early, which had sustained. ${ }^{86}$

Macfadden et $a 1^{87}$ performed a 24-month, prospective, observational study involving 532 patients with schizophrenia, during which they evaluated the effectiveness of RLAI on QOL, daily functioning, and health status. Two hundred and nine of them (39.3\%) concluded the study and 305 $(57.3 \%)$ had at least 12 months of follow-up data, which showed improvements in GAF, Strauss-Carpenter Levels of Functioning, PSP, and health status within 3 months, which continued over a period of 24 months.

Treatment with RLAI was associated with better QOL outcomes (as measured by the EuroQol [EQ]-5D, questionnaire) and lower caregiver burden, compared to other types of antipsychotics (oral conventional antipsychotics, injectable conventional antipsychotics, and oral SGA) in 1,865 Spanish patients with schizophrenia. ${ }^{88}$

\section{Paliperidone palmitate}

One multicenter, 8-week randomized, double-blind, placebo-controlled trial showed significant improvement with paliperidone palmitate (PP) versus placebo in QOL and SF-36 total and subscale scores in 404 adult inpatients with schizophrenia. ${ }^{89}$

Another clinical trial involving acutely symptomatic schizophrenic individuals found that functioning improvement could be detected following a 13-week treatment with 50 or $100 \mathrm{mg}$ equivalents of PP. ${ }^{90} \mathrm{~A}$ post hoc analysis that specifically aimed to assess the onset of efficacy of PP in markedly to severely ill patients with schizophrenia showed that PSP scores improved significantly (vs placebo) following a 13-week treatment with 75 or $100 \mathrm{mg}$ equivalents of PP, but not with a dose of $25 \mathrm{mg} .{ }^{91} \mathrm{~A} 1$-year open-label extension of a double-blind study involving 388 adult patients with schizophrenia showed that PP improved PSP scores during long-term therapy..$^{92}$ Improvements in the WHO-QoL-BREF were also found in elderly patients. ${ }^{93}$

One clinical analysis reported that the highest tested doses of PP (100 and $150 \mathrm{mg}$ ) induced significant improvements (vs placebo) in functioning scores of patients with schizophrenia who did not respond to a recent treatment with 
oral risperidone. ${ }^{94}$ However, comparative analyses indicated that PSP scores of individuals with schizophrenia receiving short-term PP therapy were not different from those observed in patients treated with oral risperidone during initiation of RLAI treatment. ${ }^{95}$

Two noninferiority analyses comparing PP and RLAI indicated that the two drugs induce comparable increases of PSP scores in schizophrenic patients. ${ }^{96,97}$ However, PP was found to be inferior to RLAI in controlling schizophrenia symptoms, when a suboptimal initiation protocol of PP was applied..$^{98}$ PALMFlexS (Paliperidone Palmitate Flexible Dosing in Schizophrenia) study, a prospective, multicenter, openlabel, 6-month, Phase IIIb interventional study, involved patients affected by schizophrenia to evaluate the effectiveness of antipsychotic therapy. In this study, 231 patients, not in an acute phase of illness, but with symptomatic schizophrenia, have switched from conventional depot antipsychotics to flexibly dosed PP due to the unsuccessfulness of the previous treatment with conventional depot antipsychotics. ${ }^{99}$ After switching to PP, more than $50 \%$ of all patients reached $\geq 20 \%$ and one-third of all patients reached $\geq 50 \%$ improvement in PANSS total score. This study highlighted relevant improvements in symptom intensity across the groups, which has been evaluated by CGI-S, subjective wellness, medication satisfaction, and patient functioning with PP.

\section{Olanzapine long-acting}

During a 8-week randomized, double-blind, placebocontrolled trial, different dosages of olanzapine long-acting (OLAI) (OLAI 210 mg/2 weeks; OLAI 300 mg/2 weeks; OLAI $405 \mathrm{mg} / 4$ weeks) induced significant ameliorations in the QLS total scores and Mental Health Scale of 404 inpatients when compared with placebo. ${ }^{100}$ Also, OLAI $210 \mathrm{mg} / 2$ weeks, $300 \mathrm{mg} / 2$ weeks, and the combined OLAI group were considered to be more effective than placebo on the Interpersonal Relations subdomain. The $300 \mathrm{mg} / 2$ weeks group and the combined OLAI group were also considered to be more effective than placebo on the Instrumental Role subdomain. In SF-36, the $300 \mathrm{mg} / 2$ weeks and $405 \mathrm{mg} / 4$ weeks OLAI groups and the combined OLAI group were also considered to be more effective than placebo on the mental component score.

OLAI was also tested in a long-term randomized study that was aimed to verify the efficacy of this drug formulation in maintenance therapy for patients with schizophrenia. The study indicated that patient QOL was significantly improved following OLAI treatment. ${ }^{101}$ An analysis of data from three clinical trials involving patients with schizophrenia using OLAI as maintenance treatment revealed that most of all patients treated with OLAI remained in a steady state or improved (62\% at 6 months and $52 \%$ at 12 months) their symptom and functioning levels. ${ }^{102}$ The study also revealed that $<8 \%$ of schizophrenia patients have had a worsening in symptoms or functioning. However, comparisons between oral olanzapine and OLAI indicated that patients experienced an increased QOL regardless of being assigned to OLAI or oral olanzapine experimental treatment groups.

There is also a secondary analysis of data received from a multicenter, randomized, open-label, 2-year study that compared the long-term therapeutic efficacy of monthly OLAI (405 mg/4 weeks; $\mathrm{n}=264$ ) with daily oral olanzapine (10 mg/day; $n=260$ ). In this study, outpatients affected by schizophrenia remained stable or improved their positive baseline level of functioning over time. ${ }^{103}$

Moreover, a 6-year, single-arm, open-label extension study of OLAI performed at 127 sites in 25 different countries on 931 patients, which have been previously enlisted in one of three clinical trials of OLAI, showed that patient satisfaction with OLAI was high. ${ }^{104}$

\section{Aripiprazole long-acting}

In a 12-week, randomized, double-blind, placebo-controlled study on 340 schizophrenia patients, Kane et al ${ }^{105}$ reported that at week 10, both psychopathology and functioning (PSP) improved, compared to placebo. Patient functioning, as evaluated by the PSP scale, remained in a steady state in stable patients receiving aripiprazole once-monthly (AOM) in two pivotal relapse studies. ${ }^{106}$ In the 52-week study, 403 patients previously treated with AOM $400 \mathrm{mg}$ were randomized to get AOM $400 \mathrm{mg}(\mathrm{n}=269)$ or placebo $(\mathrm{n}=134)$. In the 38-week study, 662 patients previously treated with oral aripiprazole were randomized to get AOM $400 \mathrm{mg}(\mathrm{n}=265)$, oral aripiprazole ( $\mathrm{n}=266)$, or AOM 50 mg (subtherapeutic dose; $n=131$ ). In the first study, there were relevant changes for the worse from baseline with placebo compared with AOM $400 \mathrm{mg}$ in PSP total score and domain scores for Personal and Social Relationships, Self-Care, and Disturbing and Aggressive Behavior. In the second study, there were relevant changes for the worse from baseline with AOM $50 \mathrm{mg}$ compared with AOM $400 \mathrm{mg}$ in PSP total score and the Personal and Social Relationships domain score.

The QUAlity of LIfe with AbiliFY Maintena ${ }^{\circledR}$ study is the first open-label, rater-blinded, head-to-head study comparing two different SGA-LAIs on health-related QOL and functioning in 295 patients. ${ }^{107}$ A statistically significant variation from baseline to week 28 on QLS total score demonstrated that AOM is more effective than PP. Moreover, in predefined analyses, significantly greater improvement with $\mathrm{AOM}$ versus 
PP was consistently demonstrated in patients $<35$ years, indicating that younger patients may benefit, in particular, from AOM $400 \mathrm{mg}$, when compared to PP.

\section{First-episode or recent-onset schizophrenia}

A few studies on only RLAI use in early stage of schizophrenia have been performed (see two recent reviews ${ }^{108,109}$ ). Moreover, specific post hoc analyses have examined patients with recent-onset schizophrenia. In this review, we will report only the studies including patient functioning and/or QOL measures.

In a 6-month open-label study by Parellada et al, ${ }^{110}$ 382 patients affected by schizophrenia and schizoaffective disorder with a disease duration of $<3$ years $(84 \%$ with a median duration of 1 year) were administered RLAI, without an oral risperidone run-in phase; $40 \%$ of them (out of $73 \%$ that completed the study) showed a $20 \%$ improvement on total PANSS. Moreover, overall functioning (GAF), quality of life (QLS), and satisfaction significantly improved.

In an open-label trial lasting 50 weeks, 64\% out of 66 stable young adults with early schizophrenia or schizoaffective illness completed the trial, showing clinical improvement ( $\geq 20 \%$ reduction in PANSS total scores). ${ }^{111}$ Patient-rated QOL (SF-36 scores) and patients' attitudes toward the medication (Drug attitude inventory scores) improved throughout the trial. Similar findings also emerged in the population of older patients.

A prospective, naturalistic, controlled, open-label study over 2 years in 50 patients with first-episode schizophrenia demonstrated fewer relapses, longer periods of compliance, and higher rates of compliance in patients treated with RLAI $(n=22)$, when compared with those treated with oral risperidone $(n=28)(68 \%$ vs $32 \%) .{ }^{112}$ RLAI was significantly more effective in reducing scores on the PANSS (10\% vs $2 \%)$ and in the CGI-S scale (10\% vs $2.5 \%$ ). Lastly, patients treated with RLAI showed a greater functional improvement $(26 \%$ increase in the final GAF score), as compared with patients on oral risperidone ( $0.5 \%$ increase in the final GAF score).

In a single-site, open-label study lasting 2 years, 50 patients with schizophreniform disorder or schizophrenia were treated with RLAI. ${ }^{113}$ Of those achieving remission according to Remission in Schizophrenia Working Group criteria (64\%), 97\% maintained this status until the end of the study, together with greater improvements in social and occupational functioning.

Significant improvements from baseline to endpoint were found in the PANSS, CGI-S, GAF, and SF-36 in 294 patients with a recent onset of schizophrenia treated with RLAI in an open-label, 6-month study. ${ }^{114}$

In a 6-month, open-label, multicenter, Phase IV trial recruiting 294 recent-onset schizophrenia patients treated with flexible doses of RLAI, patients with good premorbid functioning as assessed by Premorbid Adjustment Scale $(\mathrm{n}=142)$ showed better treatment response (PANSS, CGI-S scale, GAF scale, and SF-36), as compared with patients with stable-poor $(n=116)$ and deteriorating premorbid functioning $(n=36)$.

Clinical improvement (CGI-S), together with good reintegration rate, scarce relapses, or rehospitalization and improved social functioning (GAF) were observed in 25 patients firstly hospitalized for schizophrenia and treated with RLAI along with reintegration methods. ${ }^{115}$ Bimonthly injection associated with psychosocial methods improved interactive follow-up, thus enhancing patients' adherence to medication prescriptions.

The post hoc analyses of two observational studies (Trial for the Initiation and Maintenance Of REmission in Schizophrenia with risperidone and eSTAR) revealed that among patients on RLAI, those recently diagnosed ( $\mathrm{n}=155$ with a disease duration of $<3$ years) showed improvement in their severity of illness (CGI-S), baseline level of functioning (GAF), and length of hospitalization, when compared with patients long-term diagnosed $(n=253)$ at 12- and 24-month follow-up. ${ }^{116}$

Lastly, we found only one study using PP in patients with recent-onset schizophrenia (within 1-5 years). ${ }^{117}$ This 24-month, rater-blinded, randomized controlled study found that time to relapse was significantly longer in patients on PP $(n=352)$ versus patients treated with antipsychotic monotherapy $(n=363)$. Significantly fewer patients receiving PP met the relapse criteria, representing a $29.4 \%$ relative risk reduction compared with the oral antipsychotics arm. However, significant improvements in PSP total score, SF-36, EQ-5D, and Subjective Well-being Under Neuroleptic Treatment scale scores were observed in both treatment arms, with no significant differences observed between groups, except for a significantly greater improvement in EQ-5D index score in favor of oral antipsychotics at month 12.

\section{Refractory or TRS}

Evidence regarding a significant benefit with antipsychotics other than clozapine is still rather limited. LAIs are frequently utilized in conjugation with various oral antipsychotics. ${ }^{118}$ However, to the best of our knowledge, only two studies evaluated functioning. In the first one, a multicenter, 
prospective, 12-month follow-up observational study ${ }^{119}$ conducted in 94 patients with TRS treated with RLAI, GAF scores significantly increased in both groups of patients, the one with dopamine supersensitivity psychosis and the other one without. In the second one, a 6-month, outpatient, doubleblind, multicenter trial conducted in 160 TRS patients, RLAI 50 or $100 \mathrm{mg}$ biweekly produced clinically significant and equivalent improvement in PANSS total, positive, and negative scores, as well as global and functional measures. ${ }^{120}$

\section{Discussion}

So far, published data about the influence of LAIs (apart from RLAI) on functioning and QOL in patients with schizophrenia seem to be lacking, in terms of either quality or quantity. Most of the studies on the newer and recently released LAIs (OLAI, PP, AOM) are just focused on analyzing their efficacy and side effects profile; the few studies that investigate patients' QOL and functioning show methodological shortcomings.

First, the instruments used in the available studies do not ensure appropriate psychometrics and cannot be applied to various stages of the disease. Sometimes they are either too lengthy and prove the poor cognitive ability of patients with schizophrenia, or are too short to be meaningful.

Second, in terms of duration, clinical trials over a period of 6-8 weeks are too short to produce definitive results about the possible effects of LAIs on social functioning and QOL, because such parameters require longer time to change.

Third, improvements in social, occupational, and vocational functioning cannot be expected only by medication; other elements need to be combined in the treatment: economic support, educational actions, and real opportunities offered in daily life. Such factors have not been adequately considered in the design of clinical trials, particularly, when multicenter structures (with different levels of resources available to ensure extra clinical interventions) were involved in the research.

Fourth, analyses conducted over inpatients or outpatients have produced different results: patients' actual clinical conditions may have a relevant role on the effects produced by SGA-LAIs, but the available studies do not take it appropriately into consideration.

Bearing in mind the above-mentioned limitations, the available clinical studies do show that SGA-LAIs are effective in ameliorating patient functioning and/or QOL of patients with schizophrenia, as compared with placebo. Moreover, the significant amount of evidence in recently published RCTs and open-label studies demonstrates the superiority of RLAI versus oral antipsychotics or depot conventional antipsychotics as regards patient functioning and QOL in stable patients and no additional benefit over oral treatment in unstable patients. Furthermore, results from observational studies, which are more representative of routine clinical practice in a real-world setting, consistently showed the superior effectiveness for RLAI versus oral antipsychotics on patient functioning and QOL.

A similar efficacy was shown by RLAI and PP in direct comparative trials, suggesting that SGA-LAIs sharing a comparable receptor binding profile may induce similar effects on functioning in patients with schizophrenia. ${ }^{121}$

Not so much data are present in literature about the long-term variations in the functioning of patients with schizophrenia treated with OLAI as maintenance therapy, and it is not clear whether the observed variations are different from those observed with treatment based on oral olanzapine.

As regards AOM, the QUAlity of LIfe with AbiliFY Maintena ${ }^{\circledR}$ is the first to use a health-related QOL as a primary endpoint to compare two SGA-LAIs and is the first to show superiority of one SGA-LAI over another. Moreover, even though it was randomized, it was designed to be more naturalistic than traditional pivotal studies, as regards the inclusion criteria, as suggested by the low frequency of screening failure (22.6\%), indicating that the study did not enroll highly selected patients, which is consistent with a naturalistic setting. Lastly, the authors hypothesized that the improvement in QOL and patient functioning with AOM 400 versus PP may be attributed to the partial agonism at dopamine $\mathrm{D} 2$ receptors, which are hypothesized to modulate dopaminergic activity in the brain, thereby reducing positive symptoms and potentially improving negative and cognitive symptoms.

Also, the evidence regarding SGA-LAI use in firstepisode or recent-onset schizophrenia patients is far from conclusive, mainly as regards the duration of treatment.

Lastly, as regards the two studies conducted on TRS, it should be noted that all the patients of the Japanese study ${ }^{119}$ were TRS patients; however, none of them had tried clozapine. Moreover, none of them had problems with treatment adherence according to the study criteria. ${ }^{122}$ As regards the study of Meltzer et al, ${ }^{120}$ although the authors have hypothesized that RLAI $100 \mathrm{mg}$ would be more effective than RLAI $50 \mathrm{mg}$, no differences were found in the two groups of treatment. However, an increasing response was found during the course of the study, confirming the value of longer clinical trial duration for patients with TRS, but not superiority of the higher dose. ${ }^{120}$ 


\section{Conclusion}

The status of the research on SGA-LAIs is lacking in several aspects that may help physicians in choosing the correct drug therapy. Meaningful differences have been observed between SGA-LAIs in the onset of their clinical efficacy, and in the relationships between symptoms and functioning scores. Lastly, head-to-head studies comparing the effects of SGA-LAIs on classical measures of psychopathology and functioning are available, mainly on RLAI, while those comparing OLAI with other SGA-LAIs are still lacking.

\section{Disclosure}

The authors report no conflicts of interest in this work.

\section{References}

1. Mathers C, Boerma T, Fat DM. The Global Burden of Disease: 2004 Update. Geneva: World Health Organization; 2008. Available from: http://www.who.int/healthinfo/global_burden_disease/ GBD_report_2004update_full.pdf. Accessed November 1, 2012.

2. Murray CJ, Lopez AD. The Global Burden of Disease: A Comprehensive Assessment of Mortality and Disability from Diseases, Injuries, and Risk Factors in 1990 and Projected to 2020. Boston: Harvard University Press on behalf of the World Health Organization and the World Bank; 1996:990.

3. Bond GR. Supported employment: evidence for an evidence-based practice. Psychiatr Rehabil J. 2004;27:345-359.

4. Lehman AF. Vocational rehabilitation in schizophrenia. Schizophr Bull. $1995 ; 21: 645-656$

5. Hatfield B, Huxley P, Mohamad H. Accommodation and employment: a survey into the circumstances and expressed needs of users of mental health services in a northern town. Br J Soc Work. 1992; 22:61-73.

6. Almond S, Knapp M, Francois C, Toumi M, Brugha T. Relapse in schizophrenia: costs, clinical outcomes and quality of life. Br J Psychiatry. 2004; 184(4):346-351.

7. Alonso J, Croudace T, Brown J, et al. Health-related quality of life (HRQL) and continuous antipsychotic treatment: 3-year results from the Schizophrenia Health Outcomes (SOHO) study. Value Health. 2009; 12(4):536-543.

8. Ciudad A, Alvarez E, Bobes J, San L, Polavieja P, Gilaberte I. Remission in schizophrenia: results from a 1-year follow-up observational study. Schizophr Res. 2009;108(1-3):214-222.

9. Advokat C, Dixon D, Schneider J, Comaty JE Jr. Comparison of risperidone and olanzapine as used under "real-world" conditions in a state psychiatric hospital. Prog Neuropsychopharmacol Biol Psychiatry. 2004; 28(3):487-495.

10. Ascher-Svanum H, Nyhuis AW, Faries DE, Kinon BJ, Baker RW, Shekhar A. Clinical, functional, and economic ramifications of early nonresponse to antipsychotics in the naturalistic treatment of schizophrenia. Schizophr Bull. 2008;34(6):1163-1171.

11. Haro JM, Edgell ET, Frewer P, Alonso J, Jones PB; for SOHO Study Group. The European Schizophrenia Outpatient Health Outcomes Study: baseline findings across country and treatment. Acta Psychiatr Scand Suppl. 2003;416:7-15.

12. Silva de Lima M, de Jesus Mari J, Breier A, Maria Costa A, Pondé de Sena E, Hotopf M. Quality of life in schizophrenia: a multicenter, randomized, naturalistic, controlled trial comparing olanzapine to firstgeneration antipsychotics. J Clin Psychiatry. 2005;66(7):831-838.

13. Birchwood M, Todd P, Jackson C. Early intervention in psychosis. The critical period hypothesis. Br J Psychiatry Suppl. 1998;172:53-59.
14. Ascher-Svanum H, Zhu B, Faries DE, et al. The cost of relapse and the predictors of relapse in the treatment of schizophrenia. BMC Psychiatry. 2010;10:2.

15. Weiden PJ, Olfson M. Cost of relapse in schizophrenia. Schizophr Bull. 1995;21(3):419-429.

16. Wyatt RJ. Research in schizophrenia and the discontinuation of antipsychotic medications. Schizophr Bull. 1997;23:3-9.

17. Lieberman JA, Alvir JM, Koreen A, et al. Psychobiologic correlates of treatment response in schizophrenia. Neuropsychopharmacology. 1996;14(Suppl 3):S13-S21.

18. Lindenmayer JP, Liu-Seifert H, Kulkarni PM, et al. Medication nonadherence and treatment outcome in patients with schizophrenia or schizoaffective disorder with suboptimal prior response. J Clin Psychiatry. 2009;70(7):990-996.

19. Suzuki T, Uchida H, Takeuchi H, Tsuboi T, Hirano J, Mimura M. A review on schizophrenia and relapse - a quest for user-friendly psychopharmacotherapy. Hum Psychopharmacol. 2014;29:414-426.

20. Emsley R, Chiliza B, Asmal L, Harvey BH. The nature of relapse in schizophrenia. BMC Psychiatry. 2013;13:50-57.

21. Coldham EL, Addington J, Addington D. Medication adherence of individuals with a first episode of psychosis. Acta Psychiatr Scand. 2002;106: 286-290.

22. Tiihonen J, Haukka J, Taylor M, Haddad PM, Patel MX, Korhonen P. A nationwide cohort study of oral and depot antipsychotics after first hospitalization for schizophrenia. Am J Psychiatry. 2011;168:603-609.

23. Miller BJ. A review of second-generation antipsychotic discontinuation in first-episode psychosis. J Psychiatr Pract. 2008;14:289-300.

24. Miller BJ, Bodenheimer C, Crittenden K. Second-generation antipsychotic discontinuation in first episode psychosis: an updated review. Clin Psychopharmacol Neurosci. 2011;9:45-53.

25. Novick D, Haro JM, Suarez D, Perez V, Dittmann RW, Haddad PM. Predictors and clinical consequences of non-adherence with antipsychotic medication in the outpatient treatment of schizophrenia. Psychiatry Res. 2010;176(2-3):109-113.

26. Velligan DI, Lam F, Ereshefsky L, Miller AL. Psychopharmacology: Perspectives on medication adherence and atypical antipsychotic medications. Psychiatr Serv. 2003;54(5):665-667.

27. Velligan DI, Weiden PJ, Sajatovic M, et al. The expert consensus guideline series: adherence problems in patients with serious and persistent mental illness. J Clin Psychiatry. 2009;70(Suppl 4):S1-S46. quiz 47-48.

28. Lieberman JA, Scott Stroup T, McEvoy JP, et al. Effectiveness of antipsychotic drugs in patients with chronic schizophrenia. $N$ Engl J Med. 2005;353(12):1209-1223.

29. Kahn RS, Fleischhacker WW, Boter H, et al. Effectiveness of antipsychotic drugs in first-episode schizophrenia and schizophreniform disorder: an open randomised clinical trial. Lancet. 2008;371(9618):1085-1097.

30. DiMatteo MR. Variations in patients' adherence to medical recommendations: a quantitative review of 50 years of research. Med Care. 2004; 42:200-209.

31. Jonsdottir H, Opjordsmoen S, Birkenaes AB, et al. Medication adherence in outpatients with severe mental disorders: relation between selfreports and serum level. J Clin Psychopharmacol. 2010;30:169-175.

32. Dassa D, Boyer L, Benoit M, Bourcet S, Raymondet P, Bottai T. Factors associated with medication non-adherence in patients suffering from schizophrenia: a cross-sectional study in a universal coverage healthcare system. Aust N Z J Psychiatry. 2010;44:921-928.

33. Velligan DI, Wang M, Diamond P, et al. Relationships among subjective and objective measures of adherence to oral antipsychotic medications. Psychiatr Serv. 2007;58:1187-1192.

34. Kane JM, Kishimoto T, Correll CU. Non-adherence to medication in patients with psychotic disorders: epidemiology, contributing factors and management strategies. World Psychiatry. 2013;12:216-226.

35. Haddad B, Kishimoto T, Correlld CU, Kane JM. Ambiguous findings concerning potential advantages of depot antipsychotics: in search of clinical relevance. Curr Opin Psychiatry. 2015;28:216-221. 
36. Canadian Psychiatric Association. Clinical practice guidelines. Treatment of schizophrenia. Can J Psychiatry. 2005;50(13 Suppl 1):S7-S57.

37. Schizophrenia: Core interventions in the treatment and management of schizophrenia in primary and secondary care (update) [Internet]. National Collaborating Centre for Mental Health (UK), editors. Leicester, UK: British Psychological Society; 2009. National Institute for Health and Clinical Excellence: Guidance.

38. Buchanan RW, Kreyenbuhl J, Kelly DL, et al. The 2009 schizophrenia PORT psychopharmacological treatment recommendations and summary statements. Schizophr Bull. 2010;36:71-93.

39. Hasan A, Falkai P, Wobrock T, et al. Wfsbp Task Force on Treatment Guidelines for Schizophrenia. World Federation of Societies of Biological Psychiatry (WFSBP) guidelines for biological treatment of schizophrenia, part 2: update 2012 on the long-term treatment of schizophrenia and management of antipsychotic-induced side effects. World J Biol Psychiatry. 2013;14(1):2-44.

40. Takeuchi H, Suzuki T, Uchida H, Watanabe K, Mimura M. Antipsychotic treatment for schizophrenia in the maintenance phase: a systematic review of the guidelines and algorithms. Schizophr Res. 2012;134: 219-225.

41. Kuipers E, Yesufu-Udechuku A, Taylor C, Kendall T. Management of psychosis and schizophrenia in adults: summary of updated NICE guidance. BMJ. 2014;348:1173.

42. Moore TA, Buchanan RW, Buckley PF, et al. The Texas Medication Algorithm Project antipsychotic algorithm for schizophrenia: 2006 update. J Clin Psychiatry. 2007;68:1751-1762.

43. Malla $A$, Tibbo $P$, Chue $P$, et al. Long-acting injectable antipsychotics: recommendations for clinicians. Can J Psychiatry. 2013;58(5 Suppl 1): 30S-35S.

44. Llorca PM, Abbar M, Courtet P, Guillaume S, Lancrenon S, Samalin L. Guidelines for the use and management of long-acting injectable antipsychotics in serious mental illness. BMC Psychiatry. 2013;13:340.

45. Leucht C, Heres S, Kane JM, Kissling W, Davis JM, Leucht S. Oral versus depot antipsychotic drugs for schizophrenia - a critical systematic review and meta-analysis of randomised long-term trials. Schizophr Res. 2011;127:83-92.

46. Fusar-Poli P, Kempton MJ, Rosenheck RA. Efficacy and safety of second generation long-acting injections in schizophrenia: a metaanalysis of randomized-controlled trials. Int Clin Psychopharmacol. 2013;28:57-66.

47. Kishimoto T, Robenzadeh A, Leucht C, et al. Long-acting injectable vs oral antipsychotics for relapse prevention in schizophrenia: a metaanalysis of randomized trials. Schizophr Bull. 2014;40:192-213.

48. Schreiner A, Adamsoo K, Altamura AC, et al. A randomised, activecontrolled rated-blinded 2-year study of paliperidone palmitate versus investigators' choice of oral antipsychotic monotherapy in patients with schizophrenia (PROSIPAL). Poster presented at: CINP; June 2014; Canada: Vancouver; 22-26. Poster LP-01-013.

49. Starr HL, Mao L, Lindmayer J-P, et al. Paliperidone palmitate research in demonstrating effectiveness (PRIDE): managing schizophrenia patients with a history of incarceration and substance abuse. Poster presented at: American Psychiatric Association (APA) 167th Annual Meeting; May 3-7, 2014; New York, NY. Poster NR8-150.

50. Kishimoto T, Nitta M, Borenstein M, Kane JM, Correll CU. Long-acting injectable versus oral antipsychotics in schizophrenia: a systematic review and meta-analysis of mirror-image studies. J Clin Psychiatry. 2013; 74:957-965.

51. Suzuki T. A further consideration of long-acting injectable versus oral antipsychotics in the treatment of schizophrenia: a narrative review and critical appraisal. Expert Opin Drug Deliv. 2016;13(2):253-264.

52. Tandon R, Nasrallah HA, Keshavan MS. Schizophrenia, "just the facts" 5. Treatment and prevention. Past, present, and future. Schizophr Res. 2010;122(1-3):1-23.

53. Karow A, Moritz S, Lambert M, Schottle D, Naber D. Egofors Initiative Remitted but still impaired? Symptomatic versus functional remission in patients with schizophrenia. Eur Psychiatry. 2012;27(6):401-405.
54. Harvey PD, Heaton RK, Carpenter Jr WT, Green MF, Gold JM, Schoenbaum M. Functional impairment in people with schizophrenia: focus on employability and eligibility for disability compensation. Schizophr Res. 2012;140(1-3):1-8.

55. Wunderink L, Nieboer RM, Wiersma D, Sytema S, Nienhuis FJ. Recovery in remitted first-episode psychosis at 7 years of follow-up of an early dose reduction/discontinuation or maintenance treatment strategy: long-term follow-up of a 2-year randomized clinical trial. JAMA Psychiatry. 2013;70(9):913-920.

56. Keith S, Pani B, Nick R, et al. Practical application of pharmacotherapy with long acting risperidone for patients with schizophrenia. Psychiatr Serv. 2004;55:997-1005.

57. Lindenmayer J, Eerdekens E, Berry S, Eerdekens M. Safety and efficacy of long-acting risperidone in schizophrenia: 12 week, multicenter, open label study in stable patients switched from typical and atypical oral antipsychotics. J Clin Psychiatry. 2005;66:656-657.

58. Gastpar M, Masiak M, Latif M, Frazzingaro S, Medori R, Lombertie E. Sustained improvement of clinical outcome with risperidone long-acting injectable in psychotic patients previously treated with olanzapine. J Psychopharmacol. 2005;19:32-38.

59. Correll C. What are we looking for in new antipsychotics? J Clin Psychiatry. 2011;72:9-13.

60. Bay Y, Chen T, Wu B, et al. A comparative efficacy and safety study of long-acting risperidone injection and risperidone oral tablets among hospitalized patients: 12-week, randomized, single-blind study. Pharmacopsychiatry. 2006;39:135-141.

61. Niolu C, Bianciardi E, Di Lorenzo G, et al. Enhancing adherence, subjective wellbeing and quality of life in patients with schizophrenia: which role for long-acting risperidone? Ther Adv Psychopharmacol. 2015;5(5):278-288.

62. Lasser RA, Bossie CA, Gharabawi GM, Baldessarini RJ. Clinical improvement in 336 stable chronically psychotic patients changed from oral to long-acting risperidone: 12 month open trial. Int J Neuropharmacol. 2005;8:427-438.

63. Nasrallah HA, Duchesne I, Mehnert A, Janagap C, Eerdekens M. Health-related quality of life in patients with schizophrenia during treatment with long-acting, injectable risperidone. J Clin Psychiatry. 2004; 65:531-536.

64. Fleischhacker WW, Rabinowitz J, Kemmler G, Eerdekens M, Mehnert A. Perceived functioning and well-being and association with psychiatric symptomatology in clinically stable schizophrenia patients treated with long-acting risperidone for 1 year. Br J Psychiatry. 2005; 187:131-136.

65. Mihajlović G, Jovanović-Mihajlović N, Radmanović B, et al. Quality of life of schizophrenic patients treated with haloperidol depot and injection preparation of long-lasting risperidone. Srp Arh Celok Lek. 2011;139(Suppl 1):S36-S40.

66. Bai YM, Chen TT, Wu B, et al. A comparative efficacy and safety study of long-acting risperidone injection and risperidone oral tablets among hospitalized patients: 12-week randomized, single-blind study. Pharmacopsychiatry. 2006;39(4):135-141.

67. Arunpongpaisal S, Srisurapanont M, Kongsakon R, Kitiwattanagul K, Samanwongthai U. Risperidone long-acting injection (RLAI): the 12-week efficacy and tolerability in Thai patients with chronic schizophrenia. J Med Assoc Thai. 2010;93(3): $343-350$.

68. Osborne RH, Dalton A, Hertel J, Schrover R, Smith DK. Healthrelated quality of life advantage of long acting injectable antipsychotic treatment for schizophrenia: a time trade-off study. Health Qual Life Outcomes. 2012;10:35-43.

69. Rosenheck RA, Krystal JH, Lew R, et al. Long-acting risperidone and oral antipsychotics in unstable schizophrenia. N Engl J Med. 2011;364: $842-851$.

70. Raignoux C, Dusouchet T, Bret $\mathrm{P}$, et al. Long-acting injectable risperidone: naturalistic study in three hospitals in Aquitaine. Encephale. 2007; 33(6):973-981. 
71. Leatherman SM, Liang MH, Krystal JH, Lew RA, Valley D, Thwin SS, Rosenheck; CSP 555 Investigators. Differences in treatment effect among clinical subgroups in a randomized clinical trial of long-acting injectable risperidone and oral antipsychotics in unstable chronic schizophrenia. J Nerv Ment Dis. 2014;202:13-17.

72. Marinis TD, Saleem PT, Glue P, et al. Switching to long-acting injectable risperidone is beneficial with regard to clinical outcomes, regardless of previous conventional medication in patients with schizophrenia. Pharmacopsychiatry. 2007;40(6):257-263.

73. Möller HJ, Llorca PM, Sacchetti E, Martin SD, Medori R, Parellada E; for the StoRMi Study Group. Efficacy and safety of direct transition to risperidone long-acting injectable in patients treated with various antipsychotic therapies. Int Clin Psychopharmacol. 2005;20:121-130.

74. Curtis VA, Katsafouros K, Möller HJ, Medori R, Sacchetti E. Longacting risperidone improves negative symptoms in stable psychotic patients. J Psychopharmacol. 2008;22(3):254-261.

75. Kissling W, Glue P, Medori R, Simpson S. Long-term safety and efficacy of long-acting risperidone in elderly psychotic patients. Hum Psychopharmacol. 2007;22:505-513.

76. Lambert M, De Marinis T, Pfeil J, Naber D, Schreiner A. Establishing remission and good clinical functioning in schizophrenia: predictors of best outcome with long-term risperidone long-acting injectable treatment. Eur Psychiatry. 2010;25(4):220-229.

77. Schmaussa M, Sacchettib E, Kahnc JP, Medori R. Efficacy and safety of risperidone long-acting injectable in stable psychotic patients previously treated with oral risperidone. Int Clin Psychopharmacol. 2007; 22:85-92.

78. Lloyd K, Latif MA, Simpson S, Shrestha KL. Switching stable patients with schizophrenia from depot and oral antipsychotics to long-acting injectable risperidone: efficacy, quality of life and functional outcome. Hum Psychopharmacol. 2010;25(3):243-252.

79. Llorca PM, Bouhours P, Moreau-Mallet V; for French investigators group. Improved symptom control, functioning and satisfaction in French patients treated with long-acting injectable risperidone. Encephale. 2008;34(2):170-178.

80. Rossi A, Bagala A, Del Curatolo V, et al. Remission in schizophrenia: one-year Italian prospective study of risperidone long-acting injectable (RLAI) in patients with schizophrenia or schizoaffective disorder. Hum Psychopharmacol. 2009;24:574-583.

81. Zhao Y, Kishi T, Iwata N, Ikeda M. Combination treatment with risperidone long-acting injection and psychoeducational approaches for preventing relapse in schizophrenia. Neuropsychiatr Dis Treat. 2013;9: 1655-1659.

82. Lee NY, Kim SH, Chom SJ. A prospective, open-label study to evaluate symptomatic remission in schizophrenia with risperidone long-acting injectable in Korea. Int Clin Psychopharmacol. 2014;29:279-287.

83. Schmauss M, Diekamp B, Gerwe M, Schreiner A, Ibach B. Does oral antipsychotic pre-treatment influence outcome of a switch to long-acting injectable risperidone in patients with schizophrenia? Pharmacopsychiatry. 2010;43(2):73-80.

84. Keks NA, Ingham M, Khan A, Karcher K. Long-acting injectable risperidone v. olanzapine tablets for schizophrenia or schizoaffective disorder. Randomised, controlled, open-label study. Br J Psychiatry. 2007;191: 131-139.

85. Olivares JM, Rodriguez-Morales A, Diels J, et al. Long-term outcomes in patients with schizophrenia treated with risperidone long-acting injection or oral antipsychotics in Spain: Results from the electronic Schizophrenia Treatment Adherence Registry (e-STAR). Eur Psychiatry. 2009;24(5):287-296.

86. Lambert T, Emmerson B, Hustig H, et al. Long acting risperidone in Australian patients with chronic schizophrenia: 24-month data from the e-STAR database. BMC Psychiatry. 2012;12:25-32.

87. Macfadden W, DeSouza C, Crivera C, et al. Assessment of effectiveness measures in patients with schizophrenia initiated on risperidone long-acting therapy: the SOURCE study results. BMC Psychiatry. 2011; $11: 167-178$
88. Fe Bravo-Ortiz M, Gutiérrez-Casares JR, Rodríguez-Morales A, García MA, Hidalgo-Borrajo R. Influence of type of treatment on the well-being of Spanish patients with schizophrenia and their caregivers. Int J Psychiatry Clin Pract. 2011;15:286-295.

89. Nasrallah HA, Gopal S, Gassmann-Mayer C, et al. A controlled, evidence-based trial of paliperidone palmitate, a long-acting injectable antipsychotic, in schizophrenia. Neuropsychopharmacology. 2010;35:2072-2082.

90. Gopal S, Hough DW, Xu H, et al. Efficacy and safety of paliperidone palmitate in adult patients with acutely symptomatic schizophrenia: a randomized, double-blind, placebo-controlled, dose-response study. Int Clin Psychopharmacol. 2010;25:247-256.

91. Alphs L, Bossie CA, Sliwa JK, Ma YW, Turner N. Onset of efficacy with acute long-acting injectable paliperidone palmitate treatment in markedly to severely ill patients with schizophrenia: post hoc analysis of a randomized, double-blind clinical trial. Ann Gen Psychiatry. 2011;10:12.

92. Gopal S, Vijapurkar U, Lim P, Morozova M, Eerdekens M, Hough D. A 52-week open-label study of the safety and tolerability of paliperidone palmitate in patients with schizophrenia. $J$ Psychopharmacol. 2011;25:685-697.

93. Rama Raj P, Lewis M, Macfarlane S. Efficacy and safety of oncemonthly paliperidone palmitate long-acting injection in an elderly patient with schizophrenia. BMJ Case Rep. 2015;26:2015.

94. Sliwa JK, Bossie CA, Ma YW, Alphs L. Effects of acute paliperidone palmitate treatment in subjects with schizophrenia recently treated with oral risperidone. Schizophr Res. 2011;132:28-34.

95. Gopal S, Pandina G, Lane R, et al. A post-hoc comparison of paliperidone palmitate to oral risperidone during initiation of long-acting risperidone injection in patients with acute schizophrenia. Innov Clin Neurosci. 2011;8:26-33.

96. Pandina G, Lane R, Gopal S, et al. A double-blind study of paliperidone palmitate and risperidone long-acting injectable in adults with schizophrenia. Prog Neuropsychopharmacol Biol Psychiatry. 2011; 35:218-226.

97. Li H, Rui Q, Ning X, Xu H, Gu N. A comparative study of paliperidone palmitate and risperidone long-acting injectable therapy in schizophrenia. Prog Neuropsychopharmacol Biol Psychiatry. 2011;35: 1002-1008.

98. Fleischhacker WW, Gopal S, Lane R, et al. A randomized trial of paliperidone palmitate and risperidone long-acting injectable in schizophrenia. Int J Neuropsychopharmacol. 2011;22:1-12.

99. Hargarter L, Cherubin P, Bergmans P, et al. Intramuscular long-acting paliperidone palmitate in acute patients with schizophrenia unsuccessfully treated with oral antipsychotics. Prog Neuropsychopharmacol Biol Psychiatry. 2015;58:1-7.

100. Witte MM, Case M, Schuh KJ, Ascher-Svanum H. Effects of olanzapine long-acting injection on levels of functioning among acutely ill patients with schizophrenia. Curr Med Res Opin. 2012;28(3):315-323.

101. Godfrey JL, Detke HC, Montgomery WS, Zhao F, McDonnell D. PMH66 Quality of life and patient-reported outcomes: comparisons of individuals with schizophrenia treated with oral and long-acting injectable formulations of olanzapine. Value Health. 2009;12:17.

102. Peuskens J, Porsdal V, Pecenak J, et al. Schizophrenia symptoms and functioning in patients receiving long-term treatment with olanzapine long-acting injection formulation: a pooled analysis. BMC Psychiatry. 2012;12:130-140.

103. Ascher-Svanum H, Novick D, Haro JM, Bertsch J, McDonnell D, Detke D. Long-term functional improvements in the 2-year treatment of schizophrenia outpatients with olanzapine long-acting injection. Neuropsychiatr Dis Treat. 2014;10:1125-1131.

104. McDonnell DP, Landry J, Detke HC. Long-term safety and efficacy of olanzapine long-acting injection in patients with schizophrenia or schizoaffective disorder: a 6-year, multinational, single-arm, openlabel study. Int Clin Psychopharmacol. 2014;29:322-331. 
105. Kane JM, Peters-Strickland T, Baker RA, et al. Aripiprazole oncemonthly in the acute treatment of schizophrenia: findings from a 12-week, randomized, double-blind, placebo-controlled study. J Clin Psychiatry. 2014;75(11):1254-1260.

106. Fleischhacker WW, Baker RA, Eramo A, et al. Effects of aripiprazole once-monthly on domains of personal and social performance: Results from 2 multicenter, randomized, double-blind studies. Schizophr Res. 2014; 159:415-420.

107. Naber D, Hansen K, Forray C, et al. Qualify: a randomized head-tohead study of aripiprazole once-monthly and paliperidone palmitate in the treatment of schizophrenia. Schizophr Res. 2015;168:498-504.

108. Přikryl R, Přikrylová Kučerová H, Vrzalová M, Cešková E. Role of long-acting injectable second-generation antipsychotics in the treatment of first-episode schizophrenia: A clinical perspective. Schizophr Res Treatment. 2012;2012:764-769.

109. Heres S, Lambert M, Vauth R. Treatment of early episode in patients with schizophrenia: the role of long acting antipsychotics. Eur Psychiatry. 2014;29:1409-1413.

110. Parellada E, Andrezina R, Milanova V, et al. Patients in the early phases of schizophrenia and schizoaffective disorders effectively treated with risperidone long-acting injectable. J Psychopharmacol. 2005; 19(Suppl 5):5-14.

111. Lasser RA, Bossie CA, Zhu Y, Locklear JC, Kane JM. Long-acting risperidone in young adults with early schizophrenia or schizoaffective illness. Ann Clin Psychiat. 2007;19(Suppl 2):65-71.

112. Kim B, Lee SH, Choi TK, et al. Effectiveness of risperidone longacting injection in first-episode schizophrenia: in naturalistic setting. Prog Neuropsychopharmacol Biol Psychiatry. 2008;32:1231-1235.

113. Emsley R, Oosthuizen P, Koen L, Niehaus DJ, Medori R, Rabinowitz J. Remission in patients with first-episode schizophrenia receiving assured antipsychotic medication: a study with risperidone long-acting injection. Int Clin Psychopharmacol. 2008;23:325-331.

114. Napryeyenko O, Burba B, Martinez G, et al. Risperidone long acting injectable in recent-onset schizophrenia examined with clinician and patient self-report measures. J Clin Psychopharmacol. 2010;30: 200-202.
115. Rabinowitz J, Napryeyenko O, Burba B, et al. Premorbid functioning and treatment response in recent-onset schizophrenia: prospective study with risperidone long acting injectable. J Clin Psychopharmacol. 2011;31:75-81.

116. Dubois V, Peuskens J, Geerts P, Detraux J. Clinical outcomes of long-acting risperidone in recent versus long-term diagnosed Belgian schizophrenic patients: results from electronic Schizophrenia Treatment Adherence Registry (e-STAR) and Trial for the Initiation and Maintenance Of REmission in Schizophrenia with risperidone (TIMORES). Early Interv Psychiatry. 2014;8:39-49.

117. Schreiner A, Bergmans P, Cherubin P, et al. Paliperidone palmitate in non-acute patients with schizophrenia previously unsuccessfully treated with risperidone long-acting therapy or frequently used conventional depot antipsychotics. J Psychopharmacol. 2015;29(8):910-922.

118. Beck K, McCutcheon R, Bloomfield MA, et al. The practical management of refractory schizophrenia - the Maudsley Treatment REview and Assessment Team service approach. Acta Psychiatr Scand. 2014; 130:427-438.

119. Kimura H, Kanahara N, Komatsu N, et al. A prospective comparative study of risperidone long-acting injectable for treatment-resistant schizophrenia with dopamine supersensitivity psychosis. Schizophr Res. 2014;155:52-58.

120. Meltzer HY, Lindenmayer JP, Kwentus J, Share DB, Johnson R, Jayathilake K. A six month randomized controlled trial of longacting injectable 50 and $100 \mathrm{mg}$ in treatment resistant schizophrenia. Schizophr Res. 2014;154:14-22.

121. Ruiu S, Casu MA, Casu G, Piras S, Marchese G. Effect of controlledrelease formulations of atypical antipsychotics on functioning and quality of life of schizophrenic individuals. Expert Opin Pharmacother. 2012;13(11):1631-1643.

122. Kanaan RA. Concerns over your recent paper on risperidone longacting for treatment-resistant schizophrenia. Schizophr Res. 2015; 169:506.
Neuropsychiatric Disease and Treatment

\section{Publish your work in this journal}

Neuropsychiatric Disease and Treatment is an international, peerreviewed journal of clinical therapeutics and pharmacology focusing on concise rapid reporting of clinical or pre-clinical studies on a range of neuropsychiatric and neurological disorders. This journal is indexed on PubMed Central, the 'PsycINFO' database and CAS,

\section{Dovepress}

and is the official journal of The International Neuropsychiatric Association (INA). The manuscript management system is completely online and includes a very quick and fair peer-review system, which is all easy to use. Visit http://www.dovepress.com/testimonials.php to read real quotes from published authors. 